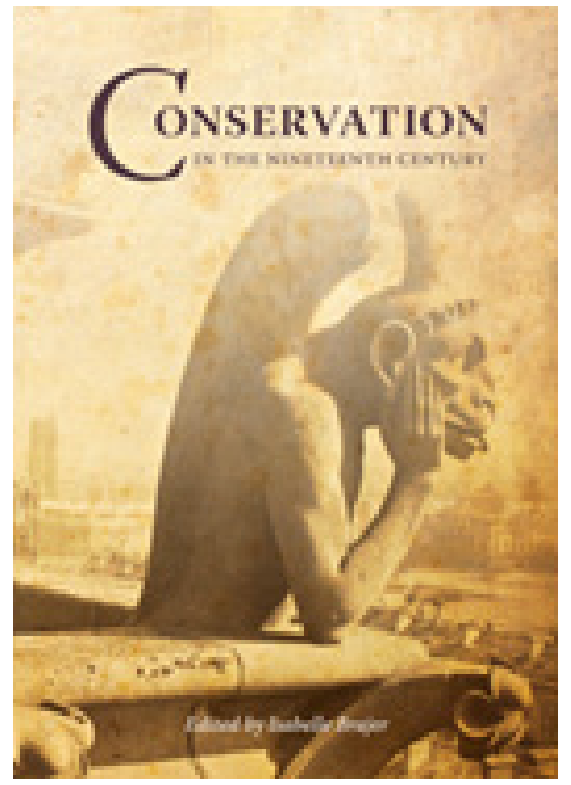

\section{Conservation in the Nineteenth Century}

\author{
Isabelle Brajer (ed.)
}

Archetype Publications in association with the National museet of Denmark and CATS (Centre for Art Technological Studies and Conservation), Copenhagen. London, 2013. 232 páginas, $220 \times 300 \mathrm{~mm}$.

ISBN: 978-1-904982-91-3.
Coordinado por Isabelle Brajer, este libro recoge las dieciocho conferencias presentadas en el congreso Conservation in the Nineteenth Century, celebrado en Copenhague, en mayo de 2013. Estas ponencias plantean cuestiones relacionadas con las tareas y técnicas llevadas a cabo por ciertos restauradores decimonónicos. Asimismo se estudian también tratamientos específicos, que han sido situados en su contexto histórico, con el fin de hacer más comprensibles las críticas y olvidos posteriores. Otra tanda de intervenciones aluden a la influencia de los avances científicos y al impacto y repercusión que tuvieron en los primeros tratados de restauración publicados, en aquel siglo, en diferentes países europeos. Predominan las cuestiones relacionadas con la pintura y la pintura mural, pero también son objeto de estudio la escultura policromada, el papel, los textiles, los instrumentos musicales y objetos de bronce, de cerámica griegos, y prehistóricos.

Aunque en el volumen no se dedica ningún comentario especializado a la figura de Viollet-le-Duc, destaca Isabelle Brajer que las referencias a sus teorías en un buen número de ponencias, prueban la influencia de sus criterios también en intervenciones de bienes muebles. Quizás por ello, de forma simbólica, se ha empleado en la portada del libro una imagen de las gárgolas que el célebre arquitecto-restaurador añadió a NotreDame de Paris. Y, en efecto, el interés por la antigüedad y por lo medieval, y el gusto por una contemplación estética de los objetos completos fue una de las más significativas características del XIX, llevándose a cabo reconstrucciones muy invasivas en todo tipo de intervenciones.
La búsqueda de rigor que predomina en la mayor parte de los trabajos se hace presente incluso cuando la falta de informes sobre los tratamientos, ha sido compensada con la aportación de recibos, notas de compra de materiales e inventarios de productos. Esta misma exigencia se percibe en los datos y contrastes facilitados por los análisis científicos.

Dado el extenso número de ponencias, una reseña de este tipo solo permite un somero recorrido meramente enunciativo por las mismas: Inicialmente, Mireille te Marvelde en su artículo -"Interpreting historical conservation terminology: cleaning' paintings in Dutch eighteenth- and nineteenth-century sources"- se centra en los problemas de terminología relacionada con la limpieza en esa época, incidiendo en los problemas planteados por la regeneración de los barnices.

Seguidamente, Cathleen Hoeniger en "Art, science and painting restoration in Napoleonic Italy, 1796-98", aporta una serie de documentos que muestran la elevada consideración que los profesionales franceses tenían de su superioridad científica. Y exigían por ello, que las obras fueran restauradas en Francia y no en Italia, aunque se enviasen historiadores a este último país para estudiar in situ los objetos artísticos.

Por otro lado Giorgio Bonsanti en "Raphael's Marriage of the Virgin in Milan and the restoration by Giuseppe Molteni (1858)", hace un interesante recorrido por el tratamiento llevado a cabo en esa maravillosa tabla por el restaurador Giuseppe Molteni. Estudiando su forma- 
ción, sus técnicas y principios; incluye, además, el informe que realizó sobre dicha obra.

Después, Matthew Hayes reflexiona sobre los tratamientos que exigían los traslados o transferencias de la pintura a otro soporte en el siglo XIX, en el trabajo "A higher reality, born of the mind: notes for a philosophy of transfer".

A la vida y obra de un restaurador de la época dedica su artículo Nicola Costaras "Richard Redgrave (18041888): first curator of paintings at the South Kensington Museum", que se señaló por incluir protecciones del reverso en los cuadros, colocar cristales por el anverso y prestar atención a los aspectos relacionados con la luz y las condiciones ambientales. Otro tanto hace Ann Hoenigswald en "Charles Chapuis: Degas' 'picture doctor' and painting restoration at the end of the nineteenth century". Este restaurador de Paris en sus etiquetas y facturas hacía notar el tipo de trabajos a los que se dedicaba: "rentoilage de tableaux, parquetage et marouflage".

A continuación, Bettina Achsel aborda el impacto y acogida que tuvo el manual de Giovanni Secco Suardo en el desarrollo de la conservación y restauración en el siglo XIX. Delphine Steyaert, por otro lado, trata de la conservación de las esculturas medievales en Bélgica en el siglo XIX y destaca la valoración de las mismas realizada por parte de la Comisión Real de Monumentos. Y Barbara Beckett aborda la técnica de la encáustica utilizada por el restaurador Franz Fernabach para sus intervenciones en pinturas murales en Alemania.

Sobre diferentes aspectos de las pinturas murales son los artículos: "Jacob Kornerup and the conservation of wall-paintings in nineteenth-century Denmark" de Susanne Ørum e Isabelle Brajer; "Documentation of medieval wall-paintings in Denmark and Germany in the nineteenth century and its impact on conservation and contemporaneous art" de Isabelle Brajer, Ursula Schädler-Saub y Susanne Ørum.

Christopher Sokolowski analiza la repercusión obtenida por un manual en Francia, "Bonnardot's Essai: a nineteenth-century restoration manual and its author". En la ponencia titulada "The test of time: nineteenthcentury innovations in paper fibre analysis", Debora D. Mayer, aborda las novedades en materia de análisis de las fibras del papel en el aquel siglo. Mientras que Maria Brunskog y Johanna Nilsson se refieren a la restauración de textiles planos "...ideological framework, ideas and treatment methods in Sweden before 1900".

Las intervenciones realizadas, en el siglo XIX, en una colección de instrumentos musicales del Musée de la Musique en Paris, constituyen la aportación de un gru- po de especialistas: Jean-Phillippe Echard, Justine Provino, Thierry Maniguet, Christine Laloue, Joël Dugot y Stephane Vaiedelich.

Otra especialidad es la tratada por Erik Risser y David Saunders, que dedican su artículo a la conservación y restauración del bronce pompeyano del Apolo Saettante del J. Paul Getty Museum. Y en otro campo incide Marie Svoboda que ha tratado de identificar las intervenciones de Raffaele Gargiulo en cuatro vasos cerámicos de la Apulia, investigación enmarcada en el proyecto The Apulian Vase Project del GCl. Finalmente, el último artículo de Helge Brinch Madsen et Jan Holme Andersen está dedicado a la preservación de objetos prehistóricos en Dinamarca entre 1807 y 1832.

A través, pues, de tan amplio recorrido, el lector puede encontrar y consultar una gran cantidad de datos muy valiosos para la profesión, tanto en materia de criterios, como de materiales y técnicas. Un libro destinado, por tanto, a convertirse en una referencia fundamental sobre la restauración europea en el siglo XIX.

Junto al anterior título, otras recientes publicaciones, en torno a la historia de la restauración, están enriqueciendo los conocimientos del pasado más inmediato de nuestra profesión, Se suman así nuevas informaciones valiosísimas tanto para los especialistas en restauración como para los interesados por las técnicas y materiales empleados en las obras artísticas. Entre ellas cabría señalar, en Francia, la de Noémie Étienne - La restauration des peintures à Paris, 1750-1815. Pratiques et discours sur la matérialité des oeuvres d'art, Presses universitaires de Rennes 2012-, o la dirigida por ella misma y Léonie Hénaut -L'Histoire à l'atelier. Restaurer les oeuvres d'art (XVIIle-XXIe siècles), Presses universitaires de Lyon 2012-, además de los volúmenes de la española Teresa Vicente Rabanaque -El restaurador de obras de arte en España durante los siglos XVIII y XIX. Nacimiento y reconocimiento de una profesión; y Del restaurador de obra de arte al conservador-restaurador de bienes culturales. La consolidación disciplinar y profesional de la restauración en España (siglos XX-XXI), Universitat Politécnica de València, Editorial UPV 2012-, por ejemplo.

Ana Calvo Manuel Universidad Complutense de Madrid 